\title{
Effects of Cooling Fluid Flow Rate on the Critical Heat Flux and Flow Stability in the Plate Fuel Type 2 MW TRIGA Reactor
}

\author{
H.P. Rahardjo* and V.I. Sri Wardhani \\ Center for Applied Nuclear Science and Technology, National Nuclear Energy Agency, \\ Jl. Tamansari 71, Bandung 40132, Indonesia
}

\section{ARTICLE INFO}

Article history:

Received 16 September 2016

Received in revised form 21 March 2017

Accepted 19 June 2017

\section{Keywords:}

TRIGA reactor

Plate fuel

Safety analysis

HEATHYD program

Critical heat flux

\begin{abstract}
A B S T R A C T
The conversion program of the 2 MW TRIGA reactor in Bandung consisted of the replacement of cylindrical fuel (produced by General Atomic) with plate fuel (produced by BATAN). The replacement led into the change of core cooling process from upward natural convection type to downward forced convection type, and resulted in different thermohydraulic safety criteria, such as critical heat flux (CHF) limit, boiling limit, and cooling fluid flow stability. In this paper, a thermohydraulic safety analysis of the converted TRIGA reactor is presented by considering the Dynamic Nucleate Boiling Ratio (DNBR) criterion, Onset Nucleate Boiling Ratio (ONBR) limit, and cooling fluid flow stability at various cooling fluid flow rate.The numerical analyses were performed using the HEATHYD program on the hottest channels of reactor core.The combination of heat transfer and fluid flow analysis were conducted for reactor operation at $2 \mathrm{MW}$ with 20 fuel element bundles and four control rod bundles. Incoming fluid flow to the cooling channel was fixed at $44.5{ }^{\circ} \mathrm{C}$ temperature and 1.9970 bar pressure, and its flow rate was varied from 1.25 to $3.5 \mathrm{~m}^{3} / \mathrm{h}$. By inputting these values, as well as the total power of fuel elements per bundle, the wall temperature distribution of the plate fuel element, cooling fluid temperature distribution, and pressure losses in the channels were obtained for the analysis of CHF limit, boiling limit, and flow stability. It was shown that no boiling occurred for the cooling fluid flow rate range of 2.4 to $3.5 \mathrm{~m}^{3} / \mathrm{h}$, and even at the cooling fluid flow rate of $1.25 \mathrm{~m}^{3} / \mathrm{h}$ where some bubbles occurred, the DNBR was higher than the critical limit (more than 23) while the flow stability criterion in some channels were slightly less than 1 (unstable). At the cooling fluid flow rate of $1.4 \mathrm{~m}^{3} / \mathrm{h}$, however, the flow became stable in all channel. The results showed that even though some bubbles start to occur, the plate-fueltype 2 MW TRIGA reactor can safely operate in the terms of CHF limit and flow stability.
\end{abstract}

() 2017 Atom Indonesia. All rights reserved

\section{INTRODUCTION}

Bandung TRIGA 2000 reactor is a research reactor built in 1964 with current maximum power of $2000 \mathrm{~kW}$, and is considered an important installation for nuclear research and education in Indonesia, due to its capability to back up the production of radioisotopes. Its operation, however, mostly depends on the fuel supplied by General

*Corresponding author.

E-mail address: henkypr@batan.go.id

DOI: https://doi.org/10.17146/aij.2017.789
Atomics (GA). Currently GA is no longer producing the TRIGA reactor fuel, but at the same time BATAN Serpong is already able to produce its own plate-type fuel. This capability should be beneficial for BATAN Bandung for keeping the TRIGA 2000 reactor operational and for performing research for long period; the refore, several researchers at BATAN Bandung planned a conversion program by converting the fuel from cylindrical to plate type, releasing it self from dependency on fuel supplies from other countries. 
The conversion program should alter the state of neutronic and thermohydraulic equilibrium in the core. Neutronically, the core structure will change the power distribution, while the cooling process will also be changed. These conditions will affect the safety limit of the core, especially its thermohydraulic aspects such as boiling limit, critical heat flux (CHF) limit, and cooling flow stability [1-4]. The Bandung TRIGA 2000 reactor used a natural convection cooling system type, but with the conversion into a square core, the cooling will be performed by means of forced convection, and the cooling fluid will flow in a very narrow channel of about $2.3 \mathrm{~mm}$ between the fuel plates.

To predict the safety limits, a cooling system analysis of the converted TRIGA 2000 reactor is required. HEATHYD program for reactor core with square fuel element, forced convection, and steady state flow was used to simulate the cooling system characteristics. Analyses were performed by inputting the power distribution of the reactor core calculated in neutronic analysis, and the necessary cooling fluid flow to avoid the heat accumulation can be calculated so that the limit of safety operations will not be exceeded.

\section{EXPERIMENTAL METHODS}

\section{Materials}

The original fuel cylinders arrangement of the Bandung TRIGA reactor inside the coreis shown in Fig. 1. About 117 fuel elements were arranged in a hexagonal form, along with five control rods. The reactor is cooled by water through the primary and secondary cooling systemsas shown in Fig. 2.

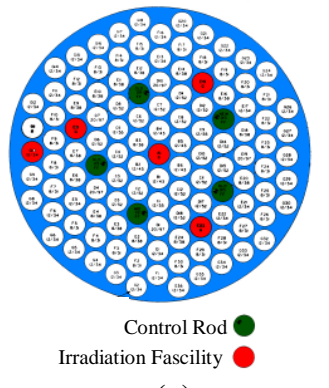

(a)

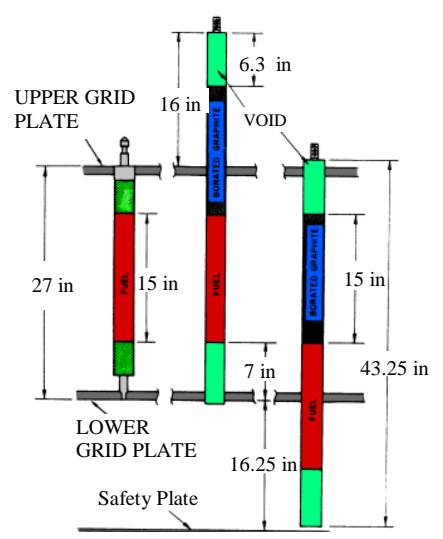

(b)
Fig. 1. (a) Core configuration of Bandung TRIGA Reactor, (b) Cylindrical fuel element.

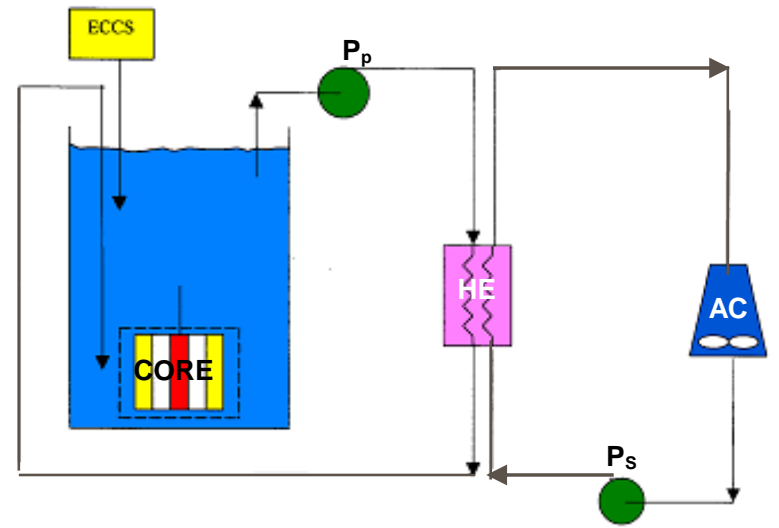

Fig. 2. Bandung TRIGA Reactor cooling system.

The hexagonal arrangement of the Bandung TRIGA reactor core was converted into a square core arrangement as shown in Fig. 3. The cooling system, which initially used natural convection with upward flow direction, was converted into a forced convection with downward flow direction as shown in Fig. 4 [5].

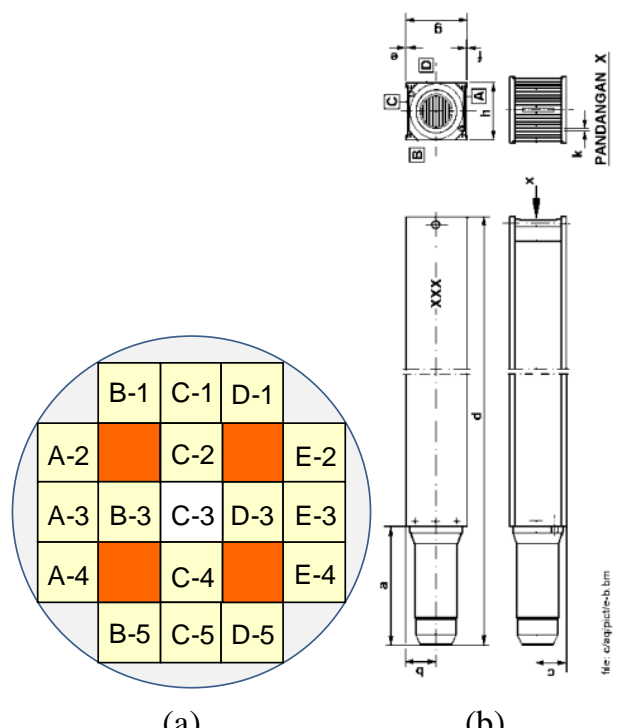

(a)

(b)

Fig. 3. (a) Core configuration of converted TRIGA Reactor, (b) Plate-type fuel.

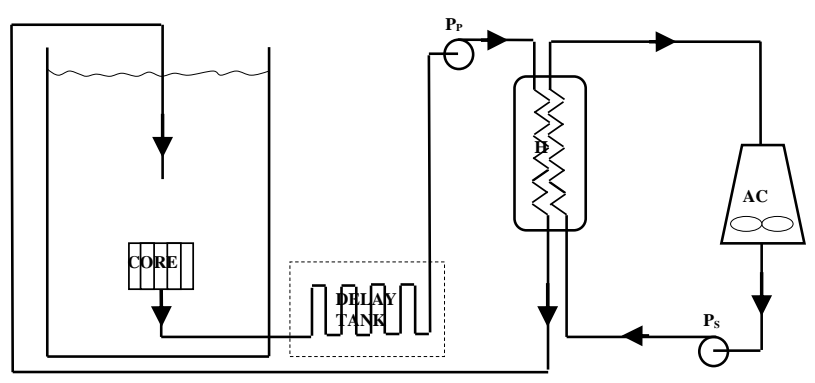

Fig. 4. Design of converted TRIGA Reactor cooling system. 
Figure 4 shows the cooling flow of the converted TRIGA reactor which differs from original Bandung TRIGA reactor by using a primary pump $\left(\mathrm{P}_{\mathrm{p}}\right)$ drawing the cooling fluid downward. This indicates that the converted TRIGA reactor uses forced convection cooling system, while the original Bandung TRIGA reactor used natural convection cooling system.

\section{Methodology}

Due to the change of behavior and direction of the cooling system, it is necessary to analyze the safety and performance of the converted cooling system. The analyses were performed numerically using the HEATHYD program [6], in the following manner (i) Collecting data such as shape, dimension, material, and thermohydraulic characteristic of the Bandung TRIGA 2000 reactor and plate-type fuel data that will be used; (ii) Providing model of the channel with highest temperature in the Bandung TRIGA 2000 reactor core using plate type fuel; (iii) Specifying boundary conditions based on the assumptions that have been stipulated; (iv) Performing thermohydraulic analysis by using HEATHYD program to see the core cooling performance in the channel with highest temperature; (v) Providing technical data for the converted TRIGA reactor that will be used in the design of the reactor cooling system.

HEATHYD is a software package developed for analysis of reactor core with square fuel type and convection cooling system in steady state flow, utilizing a combination of heat transfer and fluid flow calculations. The detailed flow diagram of the HEATHYD program is shown in Fig. 5. The inputs for HEATHYD program include (i) Number of channels in one fuel element (20), number of inner iterations (100), number of outer iteration (100), number of outputs after the outer iteration (12), and flow direction (up-down); (ii) Flow rate of the cooling $\left(1.25-1.6 \mathrm{~m}^{3} / \mathrm{h}\right)$, plate width $(67.1 \mathrm{~mm})$, plate thickness $(1.3 \mathrm{~mm})$, length of the channel $(694 \mathrm{~mm})$, inlet temperature $\left(44.5^{\circ} \mathrm{C}\right)$ and pressure (2 bar); (iii) Distance between the plates fuel elements $(2.55 \mathrm{~mm})$; (iv) Thickness of plate fuel element $(1.3 \mathrm{~mm})$; (v) Number of mesh points along the axial direction (60), parameter fuel element in axial direction ( $\cos$ or sin), the critical heat flux (Mirshak/Labuntsov correlation); (vi) Polynomial factor [6]; (vii) Power of fuel element $(0.125 \mathrm{MW})$, meat length $(620 \mathrm{~mm})$, length of cladding $(694 \mathrm{~mm})$; (viii) Thermal conductivity $(0.693 \mathrm{~W} / \mathrm{m} . \mathrm{K})$, and density of cooling fluid $\left(978 \mathrm{~kg} / \mathrm{m}^{3}\right)$; (ix) Meat width $(62.75 \mathrm{~mm})$, width of fuel element plate $(70.75 \mathrm{~mm})$; (x) Radial flux, result of neutronic calculation [12].
The results of the analysis were then used to design the converted TRIGA Reactor core cooling system. To conservatively determine the safety limit, the analysis was performed only at the channel with the highest temperature.

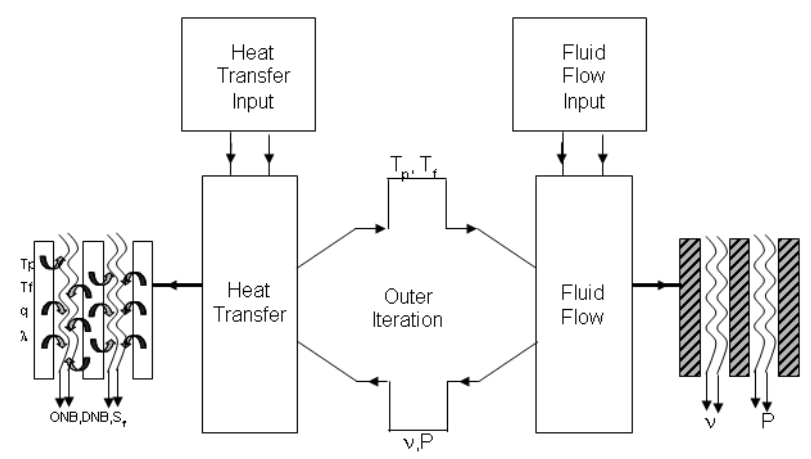

Fig. 5. Block diagram of HEATHYD program.

In the fluid flow section, flow velocity calculation at any pointwas conducted with constant mass flow rate assumption ( $\rho v A=$ constant). Related pressure drops in the channel were calculated based on [7-8].

Friction, by using equation Blassius/Colebrook;

$$
\Delta P_{f}=4 f\left(\frac{L_{W}}{D_{W}}\right)\left(\frac{1}{2} \rho v^{2}\right) \times 10^{-5}
$$

where $f=0.316 \mathrm{Re}^{-0.25}, L_{w}=$ heated length of the channel $(\mathrm{mm}), D_{w}=$ heated equivelent diameter of the channel $(\mathrm{mm}), \rho=$ density of fluid $\left(\mathrm{kg} / \mathrm{m}^{3}\right)$, $v=$ velocity of fluid $(\mathrm{m} / \mathrm{sec})$, and $\operatorname{Re}=$ Reynold number (dimensionless).

Velocity change obtained from the following Bernoulli equation,

$$
1 / 2 \rho v^{2}+P=\text { constant }
$$

with $P=$ pressure at channel.

Inlet and outlet channel cross section change, related by,

$$
\Delta P_{e n}=k_{e n}\left(\frac{1}{2} \rho v^{2}\right) \times 10^{-5}
$$

where

$$
k_{e n}=\left(\frac{1}{\beta}-1\right)^{2}+0,05
$$

and

$$
\beta=0.63+0.37\left(\frac{A_{c}}{A_{0}}\right)^{2}
$$

where $A_{c}=$ cross-sectional area in an element $\left(\mathrm{m}^{2}\right)$, $A_{0}=$ cross-sectional area of the end box immediately beyond the channel entrance/ exit $\left(\mathrm{m}^{2}\right)$. 
Gravitational potential energy change, as a function of height,

$$
\Delta P_{g}=\Delta \rho g h
$$

with $g=$ gravitational acceleration $\left(\mathrm{m} / \mathrm{s}^{2}\right)$, $h=$ height of channel (m).

In the heat transfer section, items to be calculated are as follows [9-11].

Determination Prandtl number (Pr) by,

$$
\operatorname{Pr}=\frac{C_{p} \mu}{k}
$$

where $C_{p}=$ specific heat of fluid $\left(\mathrm{kJ} / \mathrm{kg}{ }^{\circ} \mathrm{C}\right)$, $\mu=$ dynamic viscosity of fluid $(\mathrm{kg} / \mathrm{m} \mathrm{sec}), K=$ heat conductivity of fluid $\left(\mathrm{W} / \mathrm{m}{ }^{\circ} \mathrm{C}\right)$.

Convection heat transfer coefficient (h) calculated by Dittus-Boelter equation

$$
h=0.023 \operatorname{Re}^{0.8} \operatorname{Pr}^{0.4}
$$

Heat flow rate $(q ")$ at any point calculated by

$$
\begin{aligned}
& q^{\prime \prime \prime}(z)=q_{\max }^{\prime \prime \prime} \cos \frac{\pi z}{H_{e}} \text { and } \\
& q_{\max }^{\prime \prime \prime}=E \Sigma \phi_{\max }
\end{aligned}
$$

where $E=$ energy per fission $(200 \mathrm{MeV})$, $\Sigma=$ macroscopic crossection $(1 / \mathrm{cm}), \phi=$ neutron flux $\left(\mathrm{n} / \mathrm{cm}^{2} \mathrm{sec}\right)$;

The fuel cladding temperature $\left(T_{p}\right)$ and cooling fluid temperature $\left(T_{f}\right)$ at point $z$, is defined as

$$
T_{f 0}=\frac{q(z)}{\dot{m} C_{p}}+T_{f i} \text { dan } T_{P 0}=\frac{q(z)}{h A}+T_{f 0}
$$

where $\dot{m}=$ mass flow rate $(\mathrm{kg} / \mathrm{s}), T_{f i}=$ in fluid temperature $\left({ }^{\circ} \mathrm{C}\right), T_{f 0}=$ out fluid temperature $\left({ }^{\circ} \mathrm{C}\right)$, $T_{P 0}=$ out plate temperature $\left({ }^{\circ} \mathrm{C}\right)$.

Temperature difference between cladding $\left(T_{p)}\right.$ and saturated temperature cooling fluid $\left(T_{s}\right)$ calculated by Jens-Lottes equation as follows,

$$
T_{p}-T_{s}=25 \exp \left(\frac{-P}{62}\right)\left(\frac{q^{\prime \prime}}{100}\right)^{1 / 4}
$$

Heat flux distribution $\left(q_{O N B}\right)$ in the two phase condition formulated by Rohsenow [6] equation as follows,

$$
\left.q_{O N B}=\frac{P_{z}^{1,156}}{9,234}\left[1,8\left(T_{p}-T_{S}\right)\right]^{\left(0,463 P_{z}\right.}{ }^{(0,0234)}\right)^{-1}
$$

Critical heat flux $\left(q_{D N B}\right)$ is calculated by Mirshak equation as follows,

$$
q_{D N B}=151(1+0,1198 v)\left(1+0,00914 \Delta T_{\text {sub }}\right)(1+0,186 P)
$$

with $\Delta T_{s u b}=T_{s}-T_{f i}-T_{f o}$

Fluid flow stabilization $\left(S_{f}\right)$ is formulated by Whittle and Forgan [6] equation as follows,

with

$$
S_{f}=R\left(T_{s}-T_{f i}\right)\left(T_{f \mathrm{o}}-T_{f i}\right)
$$

$$
R=\left(1+\frac{25 D_{w}}{L_{w}}\right)^{-1}
$$

Boiling condition will not occur if;

$$
\frac{q_{O N B}}{q_{\text {actual }}}>1
$$

Burnout condition will not occur if;

$$
\frac{q_{D N B}}{q_{\text {actual }}}>1
$$

Fluid flow will be in unstable condition if,

$$
S_{f}<1
$$

\section{RESULTS AND DISCUSSION}

The results of the analysis with HEATHYD program include the magnitude of the heat flux during one phase and two phase wall temperature fuel elements and the temperature of the cooling fluid in maximum condition, as shown in Table 1. This analysis was conducted for the reactor operating at $2 \mathrm{MW}$ with 20 bundles of fuel elements including four pieces of control rod bundles, with the cooling fluid flow rate entering the channel varied from 1.25 to $3.5 \mathrm{~m}^{3} / \mathrm{h}$, inlet temperature of $44.5{ }^{\circ} \mathrm{C}$, and pressure of 1.9970 bar. The magnitude of the heat flux boiling $\left(q_{O N B}\right)$ was calculated by using Rohsenow equation (9), the critical heat flux $\left(q_{D N B}\right)$ calculated by using Mirshak equation (10) and the flow stability $\left(S_{f}\right)$ calculated by using Whittle and Forgan equation (11). 
Table 1. Heat Flux, Plate Temperature and Coolant Temperature

\begin{tabular}{cccccccc}
\hline Position & $\begin{array}{c}q_{A} \\
\left(\text { Watt } / \mathrm{cm}^{2}\right)\end{array}$ & $\begin{array}{c}q_{S A} \\
\left(\mathrm{Watt} / \mathrm{cm}^{2}\right)\end{array}$ & $\begin{array}{c}T_{p}(\mathrm{left}) \\
\left({ }^{\circ} \mathrm{C}\right)\end{array}$ & $\begin{array}{c}\mathrm{T}_{\mathrm{f}} \\
\left({ }^{\circ} \mathrm{C}\right)\end{array}$ & $\begin{array}{c}T_{p} \text { (right) } \\
\left({ }^{\circ} \mathrm{C}\right)\end{array}$ & $\begin{array}{c}q_{I} \\
\left(\mathrm{Watt} / \mathrm{cm}^{2}\right)\end{array}$ & $\begin{array}{c}q_{S I} \\
\left(\mathrm{Watt} / \mathrm{cm}^{2}\right)\end{array}$ \\
\hline 0 & 1.658 & 0.1466 & 125 & 81.39 & 132.1 & 2.016 & 3.517 \\
4 & 1.646 & 0.2122 & 125.7 & 82.71 & 132.1 & 2.053 & 5.181 \\
8 & 1.619 & 0.2441 & 126 & 84.03 & 132.2 & 2.08 & 7.002 \\
12 & 1.585 & 0.2638 & 126.1 & 85.35 & 132.2 & 2.103 & 9.054 \\
16 & 1.532 & 0.2223 & 125.8 & 86.65 & 132.2 & 2.105 & 10.59 \\
20 & 1.493 & 0.2278 & 125.8 & 87.95 & 132.3 & 2.123 & 13.05 \\
24 & 1.441 & 0.1959 & 125.5 & 89.22 & 132.3 & 2.127 & 15.07 \\
28 & 1.42 & 0.2529 & 126 & 90.51 & 132.3 & 2.164 & 19.38 \\
32 & 1.379 & 0.2548 & 126.1 & 91.78 & 132.4 & 2.18 & 22.93 \\
36 & 1.325 & 0.2216 & 125.8 & 93.03 & 132.4 & 2.182 & 25.76 \\
40 & 1.299 & 0.2702 & 126.2 & 94.29 & 132.4 & 2.214 & 31.46 \\
44 & 1.25 & 0.2519 & 126 & 95.53 & 132.4 & 2.22 & 35.33 \\
48 & 1.224 & 0.31 & 126.5 & 96.77 & 132.5 & 2.253 & 42.45 \\
52 & 1.161 & 0.2484 & 126 & 97.99 & 132.5 & 2.236 & 44.59 \\
56 & 1.13 & 0.2876 & 126.3 & 99.2 & 132.5 & 2.258 & 51.42 \\
60 & 1.101 & 0.3364 & 126.7 & 100.4 & 132.5 & 2.279 & 58.91 \\
\hline
\end{tabular}

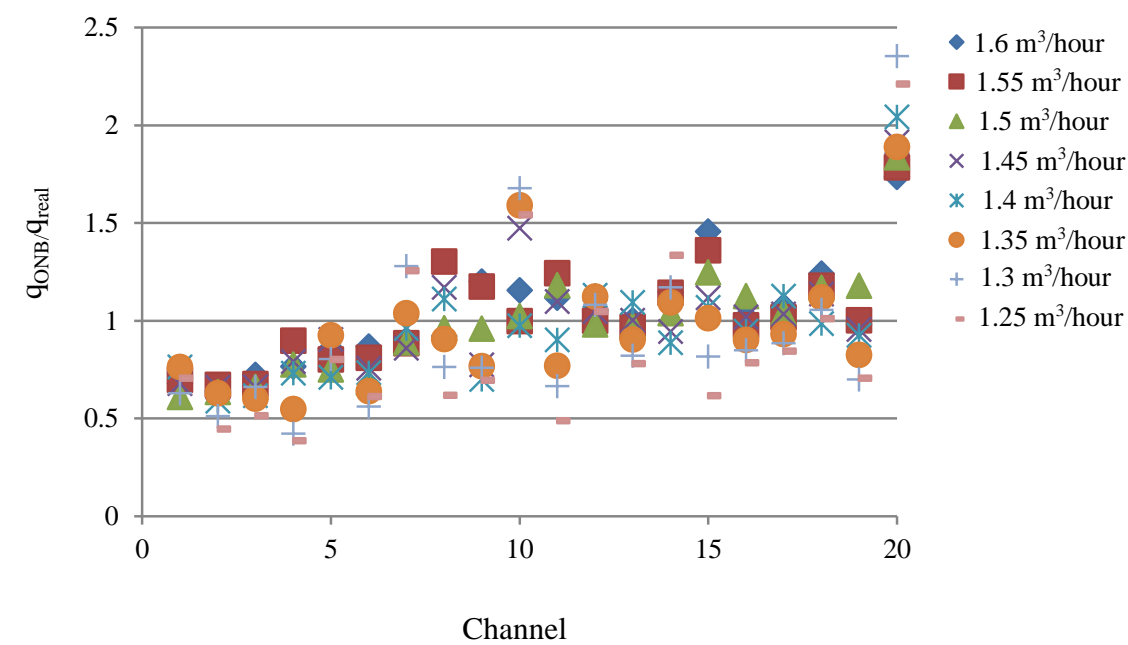

Fig. 6. Boiling in the core of a bundle channel fuel element for cooling flow variations.

To identify the boiling process, an Onset Nucleate Boiling Ratio (ONBR) was defined as the ratioof boiling heat flux $\left(q_{O N B}\right)$ to actual heat flux. When ONBR < 1, actual heat flux exceeds the boiling heat flux, thus allowing the occurrence of boiling. Figure 6 shows that at flow ratesfrom 1.25 to $1.6 \mathrm{~m}^{3} / \mathrm{h}$, the ONBRs were mostly lower than one and boiling should occur.

It can be seen from the figure that to prevent boiling, the cooling fluid flow rate should be increased. By increasing the flow rate up to $3.5 \mathrm{~m}^{3} / \mathrm{h}$, apparently the ONBR was increased, exceeding 1 at the cooling fluid flow rate of $2.4 \mathrm{~m}^{3} / \mathrm{h}$ as shown in Fig. 7 .

A further burnout condition, when the cooling fluid is not in contact with the wall and a rapid increment of cladding temperature results for even a small increment of heat flux, should be anticipated when the boiling condition has been fulfilled. The burnout fraction is defined as Dynamic Nucleate Boiling Ratio (DNBR), i.e., the ratio between critical heat flux (CHF) and actual heat flux. When DNBR $<1$, actual heat flux exceeds the $\mathrm{CHF}$, thus allowing the occurrence of burnout.

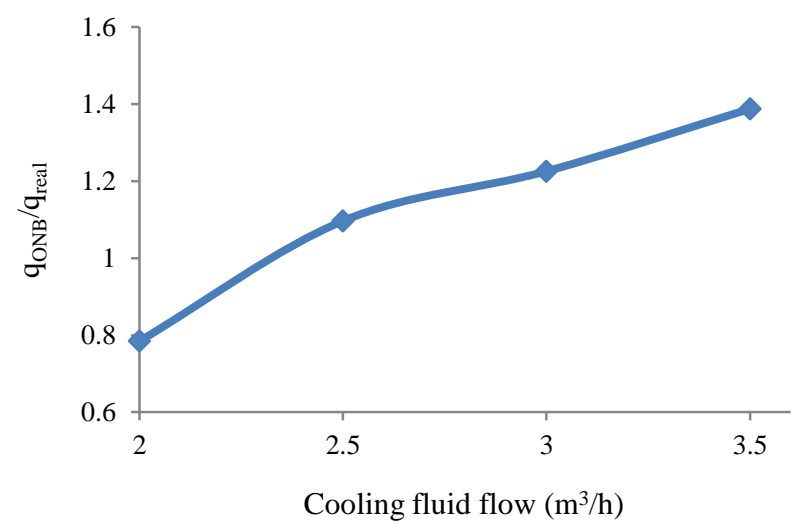

Fig. 7. Boiling in the core of a bundle channel fuel element for higher cooling flow variations.

Figure 8 shows that for flow rates of $1.25 \mathrm{~m}^{3} / \mathrm{h}$ to $1.6 \mathrm{~m}^{3} / \mathrm{h}$, DNBR exceeded 23 , much 
higher than 1. It can be concluded thatno burnout should be anticipated during the 2-MW operation with higher cooling fluid flow rate, and rapid temperature increasing in the plate fuel and core material are not likely to occur.

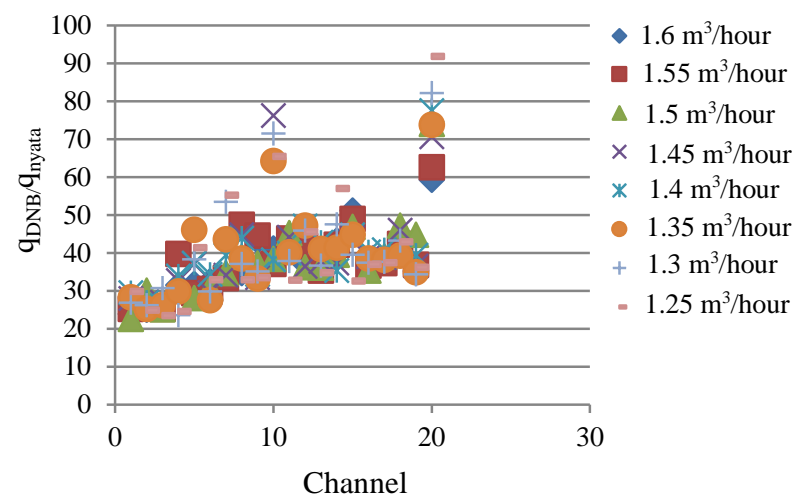

Fig. 8. Critical heat flux (CHF) in the core of a bundle channel fuel element for coolingflow variations.

As for the flow stability shown by $S_{f}$ in equation (11), if $S_{f}$ less than 1, then flow instabilities will occur. It can be seen in Fig. 9 that the cooling fluid flow across all channels remained stable, because for all the channels in a single bundle, $S_{f}$ remained higher than 1.

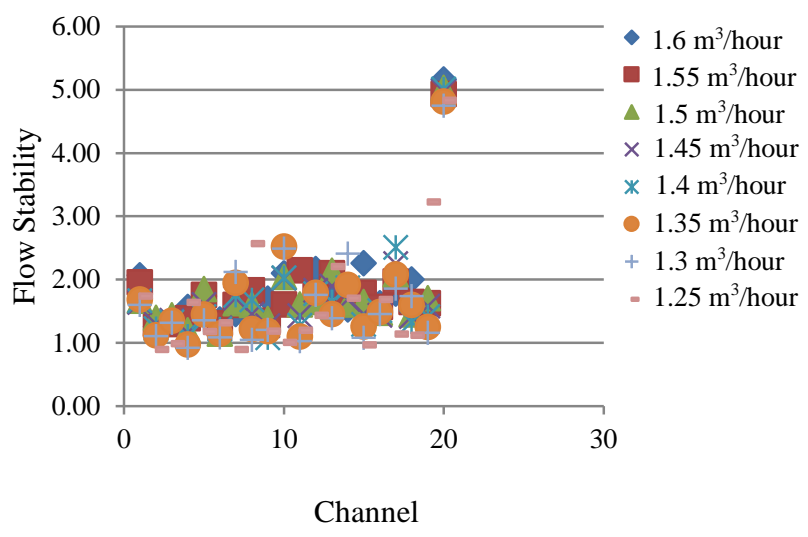

Fig. 9. Flow stabilities in the core of a bundle channel fuel element for cooling flow variations.

Figure 10 shows that the temperature of the plate was always higher than the temperature of the cooling fluid, so heat flowed from the plate to the cooling fluid. As a result,the cooling fluid temperature at the channel entry became lower than at the channel outlet. Due to this condition, the most probable location of core boiling is at the outlet (bottom side). The temperature distributions at the left and right side wall have the same tendency, with the right side wall temperature being higher than that of the left side, due to the higher heat flux on the right side.

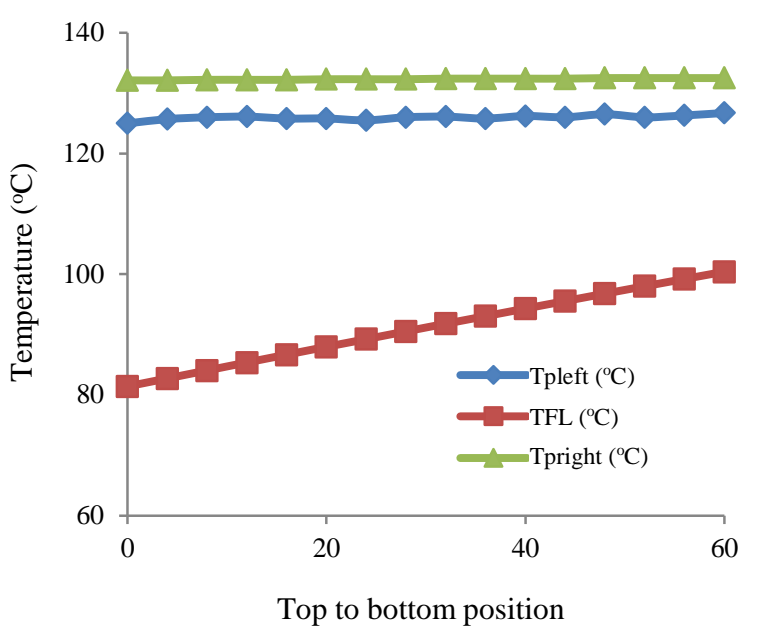

Fig. 10. Temperature distribution for wall element and cooling of channel.

\section{CONCLUSION}

A simulation of $2 \mathrm{MW}$ plate-fuel type TRIGA reactor using HEATHYD software has been performed. The results indicated that in the aspects of CHF limit and flow stability, the reactor could be safely operated at a lower cooling fluid flow rate of $1.4 \mathrm{~m}^{3} / \mathrm{h}$, even though some boiling occurred. At the cooling fluid flow rate of $2.4 \mathrm{~m}^{3} / \mathrm{h}$, no boiling occurred and the reactor should be able to operate normally.

The results of this analysis will be used as an input data for Bandung TRIGA plate-fuel reactor cooling system design to achieve safe operation of the reactor.

\section{ACKNOWLEDGMENT}

The authors would like to express their sincere thanks especially to Mr. Ilham Putranto who has provided advice on the usage of the HEATHYD software.

\section{REFERENCES}

1. C.R. Kharangate, L.E. O'Neill, I. Mudawar et al., Int. J. Heat Mass Transfer 90 (2015) 323.

2. C.E. Brennen, Thermo-hydraulics of Nuclear Reactor, Dankat Publishing Company (2014) 109.

3. X. Zhang, T. Hu, D. Chen et al., J. Nucl. Eng. Des. 304 (2016) 70.

4. D. Chandradas, K. Ghosh and D. Sanyal, Int. J. Heat Mass Transfer 90 (2015) 40. 
5. H.P. Rahardjo and V.I.S. Wardhani, The Critical Point of Conversion of Reactor TRIGA 2000 Bandung to TRIGA Reactor Fuel Plates, Proceedings of $15^{\text {th }}$ Conference on Science and Nuclear Technology, BATAN, Bandung (2015) 137. (in Indonesian)

6. R. Nabbi, Fluid Flow and Heat Transfer Model of the HEATHYD Code, in: Workshop on Reactor Physics Calculation for Applications in Nuclear Technology, World Scientific Publishing Co. Pte. Ltd. (1991) 597.

7. J. Zhang, X. Shen, Y. Fujihara et al., Ann. Nucl. Energy 76 (2015) 410.
8. Dixita, T. Hibiki, M. Ishii et al., Nucl. Eng. Des. 261(2013) 181.

9. S.J. Thiagarajan, R. Yang, C. King et al., S. Narumanchi, Int. J. Heat Mass Transfer 89 (2015) 1297.

10. D. Jo, J. Park, H. Chae, Progress in Nuclear Energy 71 (2014) 39.

11. K. Ardaneh and S. Zaferanlouei, Ann. Nucl. Energy 56 (2013) 243.

12. P. Basuki, P.I. Yazid and Zaki, Indonesian Journal of Nuclear Science and Technology 15 (2014) 69. (in Indonesian) 